\title{
NOVAS PERSPECTIVAS PARA A EFETIVIDADE DO CUMPRIMENTO DAS OBRIGAÇÕES DE PAGAR QUANTIA NO PROJETO DE REFORMA PROCESSUAL CIVIL CANADENSE COM VISTAS À TUTELA EXECUTIVA BRASILEIRA ${ }^{1 / 2}$
}

\author{
NEW PERSPECTIVES TO THE EFFECTIVENESS OF MONEY JUDGMENT \\ ENFORCEMENT IN THE CANADIAN CIVIL PROCEDURE REFORM PROJECT
} AND THE BRAZILIAN CIVIL EXECUTION

Camilo Zufelato

Livre Docente (FDRP/USP) e Doutor (FD/USP) em Direito Processual pela Universidade de São Paulo. Professor Associado de Direito Processual Civil da Faculdade de Direito de Ribeirão Preto da Universidade de São Paulo (FDRP/USP). Advogado e Parecerista. Ribeirão Preto/SP. E-mail: camilo@usp.br

Rodolfo Farias Gomes Mestrando em Direito Processual Civil na Faculdade de Direito da Universidade de São Paulo (FD/USP). Bacharel pela Faculdade de Direito de Ribeirão Preto da Universidade de São Paulo (FDRP/USP). Pesquisador visitante na Faculty of Law - University of Alberta, Canadá. Advogado. São Paulo/SP. E-mail: rodolfo@outlook.com

RESUMO: O artigo analisa os principais elementos contidos no projeto de lei canadense voltado à atualização do regramento atinente ao cumprimento judicial das obrigações de

\footnotetext{
${ }^{1}$ Artigo recebido em 20/11/2020 e aprovado em 30/03/2021.

2 Este artigo é derivado do projeto de pesquisa "O 'Uniform Civil Enforcement of Money Judgments Act' canadense: novas perspectivas para a efetividade da tutela jurisdicional", conduzido entre dezembro de $2017 \mathrm{e}$ fevereiro de 2018 na University of Alberta, Canadá, com fomento da Fundação de Amparo à Pesquisa do Estado de São Paulo (FAPESP) por meio de bolsa estágio de pesquisa do exterior, em processo de submissão contínua, e acompanhamento dos professores Tamara Buckwold e Roderick Wood, acadêmicos canadenses que integraram a comissão legislativa que elaborou a lei modelo ora em estudo.
} 
pagar quantia, que, diferentemente do Código de Processo Civil brasileiro, rejeita o uso da suspensão de licenças de devedores como instrumento de apoio nas execuções. Comparando a proposta de reforma legislativa canadense com a sistemática das execuções brasileiras, o artigo pretende ressaltar os pontos de encontro e divergência entre os diplomas legais em análise, destacando possíveis alternativas para a efetividade do cumprimento das obrigações de pagar quantia no direito brasileiro.

PALAVRAS-CHAVE: Direito canadense; execução; obrigação de pagar quantia; medidas de apoio; efetividade.

ABSTRACT: The article analyses the main features of the 2005 Canadian Uniform Civil Enforcement of Money Judgment Act, a model law aimed at revamping and uniformizing the provisions regarding the enforcement of money judgments across the country, which, unlike the 2015 Brazilian Civil Procedure Code, rejects the use of civil licenses suspension as a legal remedy to enforce this kind of debt. Comparing this law reform proposal with the Brazilian execution systematic, the article aims to highlight the similarities and differences between these two legal systems, searching for alternatives to the effectiveness of money judgments enforcement in Brazilian Law.

KEYWORDS: Canadian Law, judgment enforcement; money judgment; legal remedy; effectiveness.

\section{INTRODUÇÃO}

A garantia do cumprimento das decisões judiciais impõe-se como questão central no Direito moderno, diante da imperatividade de um sistema legal ser capaz de fornecer ao titular do direito não apenas uma decisão em seu favor, mas, talvez ainda mais importante, instrumentos adequados e efetivos para vê-la cumprida. ${ }^{3}$ Naturalmente, isto inclui o cumprimento judicial das obrigações de pagar quantia, seja no âmbito do cumprimento de

\footnotetext{
${ }^{3}$ CINTRA, Antonio Carlos Araujo; GRINOVER. Ada Pellegrini; DINAMARCO, Cândido Rangel. Teoria Geral do Processo. $26^{\mathrm{a}}$ ed. São Paulo: Malheiros, 2010. p. 41
} 
sentença (art. 513 e seguintes, do CPC), seja por meio da execução de títulos extrajudiciais (art. 771 e seguintes, do CPC).

No entanto, considerando que o cumprimento judicial de obrigações desta natureza depende frequentemente da expropriação dos bens dos devedores, muitos são os obstáculos que atrasam ou mesmo impedem que a tutela executiva seja bem-sucedida: procedimentos complexos e custosos ou a ausência de instrumentos para o alcance de determinados ativos, especialmente de devedores relutantes, são falhas comuns nos sistemas de execução de decisões e títulos extrajudiciais em muitos países. ${ }^{4}$ Por estes motivos, perseguir débitos judicialmente costuma ser uma tarefa trabalhosa, podendo levar décadas até seu desfecho, o que acarreta um sentimento generalizado de que os credores podem até ganhar o processo, mas, provavelmente, não levarão o "prêmio" para casa.

Deveras, nos últimos anos, alguns países promoveram reformas substanciais em seus regramentos jurídicos relativos à temática das execuções, a fim de remodelar sistemas ineficientes, que careciam de recursos adequados para satisfazer os direitos e expectativas dos credores.

No Brasil, a mudança mais significativa neste campo certamente está contida - ainda que indiretamente ${ }^{5}$ - no artigo 139, IV, do Código de Processo Civil de 2015, que permite aos juízes "determinar todas as medidas indutivas, coercitivas, mandamentais ou subrogatórias necessárias para assegurar o cumprimento de ordem judicial, inclusive nas ações que tenham por objeto prestação pecuniária". Este mecanismo já era previsto, em certa medida, ao cumprimento das obrigações de fazer e não fazer (art. 461, do CPC 1973) e de dar coisa (art. 461-A, do CPC 1973), mas apenas no novo Código de Processo Civil foi estendido para abarcar também as obrigações de pagar quantia, permitindo a adoção de

\footnotetext{
${ }^{4}$ Por exemplo, na França, onde os astreintes fornecem base para a ampla e forte coerção dos réus a cumprirem obrigações personalíssimas através da aplicação de multas diárias em benefício do credor, não existem medidas coercivas específicas que efetivamente permitam a execução das obrigações de pagar quantia, uma vez que a imposição de sanções pecuniárias não parece ter muito efeito sobre os devedores que aparentam não possuir bens. Do mesmo problema sofre o processo civil italiano, que tradicionalmente rejeitava a adoção de medidas coercitivas atípicas e só recentemente abraçou os astreintes, em um espectro de aplicação muito mais restrito do que o francês. Cf. BONATO, Giovanni. As reformas da execução no processo civil italiano. Civil Procedure Review, v. 6, n. 3, p. 129-158, 2015.

${ }^{5}$ Conforme a topografia do Código de Processo Civil de 2015, o dispositivo encontra-se inserido no título "Do juiz e dos auxiliares da justiça", figurando como primeiro artigo do capítulo I, intitulado "Dos poderes, dos deveres e da responsabilidade do juiz.
} 
soluções criativas e amoldadas à situação concreta (ex. suspensão de passaporte, habilitação automotiva e cartões de crédito), conferindo, assim, maior efetividade ao processo. ${ }^{6}$

Alguns requisitos para a aplicação dessas medidas têm sido sugeridos pela literatura acadêmica e pela jurisprudência, como a evidência de ocultação de patrimônio pelo devedor e o esgotamento de todos os instrumentos tradicionais de expropriação antes do uso de medidas atípicas, a fim de evitar abusos em sua aplicação. ${ }^{7}$ A despeito disto, muitas são as críticas a este dispositivo, variando da quantidade de poder coercitivo dado ao arbítrio dos juízes à mudança da exigibilidade patrimonial para a coerção pessoal. ${ }^{8}$

Sobre este tema, relevante a experiência canadense, cujas normas processuais, até a década passada, eram tão ineficientes quanto às dos demais países. Todavia, este cenário começou a mudar a partir de 2005, com a elaboração da "Uniform Civil Enforcement of Money Judgments Act” ("Lei Modelo de Cumprimento Judicial das Obrigações de Pagar Quantia", em tradução livre), um projeto de lei uniforme voltado à modernização do cumprimento de decisões cujo conteúdo seja o dever de pagar quantia, a partir da atualização e padronização das normas de processo civil entre as províncias do país. ${ }^{9}$

Importante destacar que, embora o país tenha se empenhado em reformular e dar maior efetividade aos procedimentos executórios, propondo, por exemplo, a ampliação do rol de bens penhoráveis e do papel dos agentes administrativos no processo de expropriação, a aplicação de medidas coercitivas atípicas foi expressamente recusada neste projeto de lei, diante do potencial altamente punitivo de tais instrumentos - indicando, outrossim, que seu uso pode não ser exatamente necessário para alcançar uma melhor tutela ao credor.

Em realidade, a suspensão de licenças e até mesmo prisão de devedores por curto período podem ser impostas no Canadá, com base em leis relativas à execução de alimentos

\footnotetext{
${ }^{6}$ GAJARDONI, Fernando da Fonseca. A revolução silenciosa da execução por quantia. JOTA. Brasília DF: 24 ago. 2016. Disponível em <https://www.jota.info/opiniao-e-analise/artigos/a-revolucao-silenciosa-daexecucao-por-quantia-24082015>.

${ }^{7}$ MEDEIROS NETO, Elias Marques. O artigo 139, IV, do novo código de processo civil: a atipicidade dos meios executivos. In: JATAHY, Carlos Roberto; ALMEIDA, Diogo Assumpção Rezende de; AYUOUB, Luiz Roberto (Coord.). Reflexões sobre o novo código de processo civil. Rio de Janeiro: FGV Editora, 2016.

${ }^{8}$ RODOVALHO, Thiago. O necessário diálogo entre a doutrina e a jurisprudência na concretização da atipicidade dos meios executivos. JOTA. Brasília DF: 21 set. 2016. Disponível em <https://www.jota.info/opiniao-e-analise/artigos/o-necessario-dialogo-entre-doutrina-e-jurisprudencia-naconcretizacao-da-atipicidade-dos-meios-executivos-21092016>.

${ }^{9}$ UNIFORM LAW CONFERENCE OF CANADA. Uniform Civil Enforcement of Money Judgments. 2005. Disponível em <http://www.bcli.org/project/uniform-civil-enforcement-money-judgments-act>.
} 
e sanções com base no Código de Trânsito, sendo, no entanto, hipóteses extremamente restritas. ${ }^{10}$

Conforme pontuou a Comissão de Reforma Legislativa da província da Nova Escócia, "há um aspecto altamente punitivo nesses instrumentos que, embora convenientes à execução de alimentos, não se adequam aos demais tipos de execução. Filosoficamente, o inadimplemento da dívida não é considerado uma questão de punição; em vez disso, a lei prevê instrumentos razoáveis para permitir a apreensão e venda dos bens e rendimentos do devedor. [...] Também nos preocupam os riscos morais de se permitir a suspensão de licenças, o que poderia ser usado por credores inescrupulosos para ameaçar devedores relativamente vulneráveis, forçando-os, no limite, a liquidar ativos que estão sujeitos ao regime das impenhorabilidades para se verem livres da cobrança". ${ }^{11}$

Ainda há muito debate na academia e nos tribunais brasileiros sobre os reais limites da aplicação de medidas coercivas no cumprimento das obrigações de pagar quantia, sem nenhuma conclusão até o momento, de modo que experiências internacionais, como a canadense, podem ajudar a vislumbrar alternativas para o problema das execuções, sem deixar de observar direitos fundamentais de credores e devedores.

Assim, diante das recentes propostas de avanços ao direito canadense na temática das execuções, adotando sentido distinto do direito brasileiro, o presente artigo se propõe a analisar os instrumentos de cumprimento das obrigações de pagar quantia no direito canadense, comparando-os com o procedimento de execução previsto no CPC, em busca de novas perspectivas para a efetividade no processo civil brasileiro.

\section{TRADIÇÕES LEGAIS CANADENSES E O PROCESSO CIVIL}

\footnotetext{
${ }^{10}$ LAW REFORM COMISSION OF NOVA SCOTIA. Final Report: Enforcement of Civil Judgments. 2014. Disponível em <http://www.canlii.org/t/7f5>.

${ }^{11}$ Tradução livre de "there is a highly punitive aspect to these remedies that, while appropriate in the area of family maintenance enforcement, is less so in the context of judgment recovery. Philosophically, non-payment of debt is not considered a matter for punishment; rather, the law makes every provision within reason to permit seizure and liquidation of the debtor's assets and income. We are also concerned about the moral hazards of making license suspension available, where the prospect of suspension could be used by vulnerable debtors. In turn, those debtors might feel obliged to liquidate or surrender assets or income that are subject to statutory exemptions". Ibidem, pp. 108-109.
} 
O sistema jurídico canadense tem como base a Common Law inglesa, herança proveniente de sua posição como ex-colônia britânica e posterior membro da Commonwealth das Nações. A estrutura legal canadense é também bi-jurisdicional, de modo que algumas áreas do direito são de competência legislativa stricto sensu do Parlamento Federal, enquanto que outras são regulamentadas pelas assembleias provinciais e territoriais, além de serem orientadas por regras do direito comum. ${ }^{12}$

A opção por este sistema é, em parte, reflexo da própria estrutura cultural do país. Conforme aponta Barbara Billingsley, "a decisão de tornar o Canadá uma federação resultou da necessidade de acomodar os interesses religiosos, linguísticos e culturais dos católicos de língua francesa em um país predominantemente povoado por protestantes de língua inglesa". ${ }^{13}$

Embora o sistema de precedentes e a doutrina do stare decisis sejam elementos indissociáveis do direito canadense, a legislação estatutária/codificada elaboradas pelo Parlamento e pelas assembleias legislativas provinciais e territoriais vem desempenhando, cada vez mais, papel central no país, promovendo respostas ágeis à mudança de valores na sociedade e às novas situações jurídicas dela decorrentes.

Isto inclui as regras relativas ao cumprimento das decisões judiciais, que, embora de competência legislativa de cada província ou território, compartilham em todo o país as mesmas falhas e instrumentos ineficazes para garantir os direitos do credor após uma decisão judicial, tendo sido descritas pela doutrina como "uma colcha de retalhos de legislação inglesa e canadense e regras jurisprudenciais que não se encaixam em um padrão abrangente ou viável". ${ }^{14}$

De fato, historicamente, a disciplina do cumprimento das decisões judiciais no Canadá careceu de coesão e consistência, resultando em questões desafiadoras neste campo. Alguns tipos de bens não podiam ser alcançados facilmente; outros, de maneira alguma.

\footnotetext{
${ }^{12}$ BILLINGSLEY, Barbara. Evolution, Not Revolution: Canada's Constitutional History and the Constitution Act, 1867. LawNow, v. 37, p. 8, 2012. Cabe aqui notar que a província de Quebec figura como exceção no quadro apresentado, por motivos histórico, sendo regida pelo sistema da Civil Law, influenciada pelo direito de seus colonizadores franceses. Deste modo, as acepções acerca do direito canadense adotadas neste artigo são limitadas àquelas relacionadas às das províncias e territórios de Common Law.

${ }^{13}$ Ibidem, loc. cit. Tradução livre de: "the decision to make Canada a federation resulted from the recognized need to accommodate religious, linguistic and cultural interests of French-speaking Catholics in a country predominantly populated by English-speaking Protestants".

${ }^{14}$ DUNLOP, Charles Richard Bentley. Creditor-Debtor Law in Canada. $2^{\text {nd }}$ ed. Toronto: Carswell, 1995. p. 9
} 
Além disso, como mencionado antes, as disposições canadenses sobre a execução derivaram da Common Law inglesa e das tradições de equidade, mas foram amplamente influenciadas por sucessivos precedentes e reformas de legislação estatutária que não seguiram um padrão coeso, acarretando um sistema bastante confuso e frequentemente ineficiente, tanto da perspectiva de credores quanto de devedores. ${ }^{15}$

Durante as últimas duas décadas, apenas as províncias de Alberta e Saskatchewan promulgaram reformas substanciais sobre a legislação que rege o cumprimento das decisões judiciais cujo conteúdo versa uma obrigação de pagar quantia.

Justamente com base nas experiências e avanços promovidos por estas duas províncias, a Conferência de Direito Uniforme do Canadá (ULCC) apresentou, em 2005, a Lei Modelo de Cumprimento Judicial das Obrigações de Pagar Quantia, uma proposta de lei estatutária que visa harmonizar as legislações provinciais em relação ao assunto, além de fornecer instrumentos e remédios que permitam o efetivo cumprimento dos direitos do credor.

Embora nenhuma província tenha ainda adotado integralmente a Lei Modelo, o ato uniforme já foi aprovado em New Brunswick, onde aguarda início da vigência. Além disso, instituições governamentais da Nova Escócia e a Colúmbia Britânica publicaram relatórios recomendando a adoção da Lei Uniforme, com algumas emendas.

\section{O UNIFORM CIVIL ENFORCEMENT OF MONEY JUDGMENTS ACT: PRINCIPAIS NOVIDADES}

No Canadá, a precária integração entre os procedimentos importados da Common Law e aqueles previstos na legislação estatutária de cada província resultou em um sistema de execuções ineficiente, moroso e caro. Diante disto, com o objetivo de superar esses problemas e fornecer métodos abrangentes e eficientes para o cumprimento das obrigações de pagar quantia em todo o país, a Conferência de Legislação Uniforme do Canadá propôs, em 2005, a adoção da "Uniform Civil Enforcement of Money Judgments Act”, lei modelo que será objeto de análise deste capítulo.

\footnotetext{
${ }^{15}$ Ibidem, loc. cit.
} 
Considerando a extensão do projeto - que compreende mais de duzentas seções optou-se por destacar tão somente as principais características desenhadas pela Comissão e que representam o núcleo fundamental da proposta de reforma.

\subsection{Exigibilidade universal e unificação dos procedimentos de expropriação}

Uma grande falha - ou pelo menos lacuna - na legislação de execução civil préreforma consistia na necessidade de existência de regulamentações específicas para a expropriação de cada classe de ativos. Por este motivo, alguns bens simplesmente não podiam ser alcançados por um credor devido à falta de um instrumento que visasse esses ativos, ou, mesmo quando um instrumento judicial estava disponível, o procedimento envolvido não era exatamente claro ou efetivo. ${ }^{16}$

Visando superar esse problema, a Lei Uniforme adota como um de seus princípios fundamentais a exigibilidade universal dos bens dos devedores, o que significa que todos os bens e direitos de um devedor podem ser alcançados a fim de satisfazer uma obrigação de pagar quantia durante o procedimento de execução, excetuando-se apenas aqueles bens que foram deliberadamente definidos impenhoráveis pela lei - como o bem de família e parte do salário do devedor. ${ }^{17}$ Este princípio já havia sido implementado nas províncias de Alberta, Nova Escócia e Saskatchewan, em reformas pontuais, representando forte avanço frente a um sistema desatualizado e falho. ${ }^{18}$

A fim de promover a concretização desse princípio, a Lei Uniforme prevê um método unificado de expropriação de bens, substituindo uma série de mecanismos compartimentados por um procedimento único e amplo. ${ }^{19}$

Neste ponto, cumpre ressaltar característica peculiar do sistema de execuções canadense, em que o "sheriff” (oficial de execução, em tradução livre) desempenha papel central. As funções específicas deste funcionário administrativo diferem de província para província, podendo ser diretamente responsável pela apreensão e venda de bens de um

\footnotetext{
${ }^{16}$ BUCKWOLD, Tamara M. The Reform of Judgment Enforcement Law in Canada: An Overview and Comparison of Models for Reform. Sask. L. Rev., v. 80, 2017. p. 76. Por exemplo direitos de opção societária e equity privada não podiam ser alcançados pela legislação pré-reforma.

${ }^{17}$ UNIFORM LAW CONFERENCE OF CANADA, op. cit, Seção 50 (1).

${ }^{18}$ LAW REFORM COMISSION OF NOVA SCOTIA, op. cit., p. 13.

${ }^{19}$ GLEIXNER, Micheline A.; LEBLANC, Natalie H.; MORISSET, Sacha D. The New Brunswick Judgment Enforcement Act: Has Its Time Finally Come. UNBLJ, v. 63, p. 280, 2012. p. 289.
} 
devedor ou, quando não, pelo estabelecimento e supervisão de contratos com agências privadas responsáveis pela condução dos procedimentos de expropriação. Isso significa que o cumprimento de sentenças no Canadá é basicamente um procedimento administrativo, dispensando a participação do juiz como coordenador do processo de execução. ${ }^{20}$

Sob o regramento da Lei Uniforme, o oficial de execução realiza o procedimento de expropriação adequado conforme o tipo de bem envolvido ou por qualquer outro método que seja ordenado pelo tribunal. ${ }^{21}$

Isso acarreta duas repercussões práticas. A primeira é que, ao apresentar uma lista abrangente de métodos de execução a serem adotados por um oficial contra todos os tipos de ativos, eventualmente complementada por uma ordem do tribunal se exigido pelas peculiaridades do caso, a Lei Uniforme prevê instrumentos eficientes oponíveis contra todos os bens de um devedor.

A segunda, mais indireta, mas não menos relevante, decorre do fato de que o sistema reformado contempla a execução por meio de apenas um funcionário, em comparação com o sistema antigo, sob o qual algumas funções eram desempenhadas pelo "sheriff", outras pelo oficial de justiça e ainda algumas sob a direção do próprio tribunal. No sistema reformado, os procedimentos de execução não dependem, a priori, de autorizações judiciais após a prolação da sentença ou da obtenção do título extrajudicial. O credor pode iniciar o processo de penhora instruindo diretamente o agente de execução e fornecendo-lhe as informações básicas necessárias para o êxito da execução.

Esses fatores combinados reduzem a complexidade da execução da sentença e tornam o procedimento substancialmente menos demorado e oneroso para os credores.

\subsection{Tutela provisória}

\footnotetext{
${ }^{20}$ Em verdade, esta característica é compartilhada por diversos sistemas de execução fundados na common law, como o norte-americano, o inglês e o escocês, bem como por jurisdições de tradição romano-germânica, incluindo Itália, Espanha e, mais recentemente, Portugal. Cf. RIBEIRO, Flávia Ribeiro. Desjudicialização da execução civil: mito ou realidade. Migalhas. São Paulo SP: 18 out. 2019. Disponível em <https://migalhas.uol.com.br/depeso/313285/desjudicializacao-da-execucao-civil-mito-ou-realidade〉. HILL, Flávia Pereira. Desjudicialização da execução civil: reflexões sobre o projeto de lei no 6.204/2019. Revista Eletrônica de Direito Processual, v. 21, n. 3, 2020. HILL. Flávia Pereira. O procedimento extrajudicial préexecutivo (Pepex): reflexões sobre o modelo português, em busca da efetividade da execução no Brasil. In: MEDEIROS NETO, Elias Marques de; RIBEIRO, Flávia Pereira. Reflexões sobre a Desjudicialização da Execução Civil. Curitiba: Juruá. 2020. pp. 305-322.

${ }^{21}$ UNIFORM LAW CONFERENCE OF CANADA, op. cit., Seção 52 (1).
} 
O percurso de um credor até a obtenção de uma decisão judicial em seu favor é quase sempre moroso, influenciado pelo alto volume de trabalho nos tribunais, bem como pela complexidade e extensão dos procedimentos. Tal hiato pode ser extremamente desfavorável à parte em questão, não apenas pela demora na resolução do litígio em si, mas também porque um devedor relutante pode se aproveitar desse período para transferir ou dissipar seus ativos, tornando o longo processo, ao seu final, simplesmente infrutífero. ${ }^{22}$

Embora uma medida nos estágios iniciais de um processo que restrinja a capacidade do devedor em dispor de seus bens possa aumentar as chances de um resultado profícuo, ela pode também ser uma ferramenta perigosa sob a perspectiva do devedor. A concessão de uma tutela de natureza provisória precede a consideração do tribunal sobre o mérito do caso, que pode se modificar de acordo com o desenvolvimento do processo e da cognição judicial. Além disso, nem o réu, nem os terceiros-interessados têm a oportunidade de apresentar defesas e provas antes da decisão, dando ao demandante forte poder para pressionar o devedor a pagar a dívida. ${ }^{23}$

A fim de resolver esta questão e equilibrar os dois lados da disputa, muitas jurisdições ao redor do mundo fornecem instrumentos que permitem, sob certas circunstâncias e condições, que uma parte dos ativos do réu seja arrestado a fim de garantir sua disponibilidade após eventual sentença de procedência. Na legislação canadense préreforma, esses recursos estavam dispersos em uma infinidade de opções disponíveis, cada um deles com requisitos e procedimentos específicos. Dentre estes, encontravam-se as ordens de indisponibilidade, intervenção em empresas em estado pré-falimentar e bloqueios em folha de pagamento. ${ }^{24}$

Essa diversidade de instrumentos foi alvo de muitas críticas, devido à excessiva compartimentação e formalidades que exigiam, levando à ausência de um regramento coerente de preservação patrimonial, com requisitos e procedimentos bem definidos. ${ }^{25}$ Além disso, o próprio réu poderia ser prejudicado pela falta de um recurso único, estando

\footnotetext{
${ }^{22}$ BUCKWOLD, op. cit. p. 77

${ }^{23}$ ALBERTA LAW REFORM INSTITUTE. Prejudgment Remedies for Unsecured Claimants. Report $\mathrm{n}^{\circ} 50$, 1988. p. 133-135.

${ }^{24}$ CUMING, Ronald C.C.; LAYH, Donald. The Saskatchewan Enforcement of Money Judgments Act: Commentary and Analysis. Regina: Queen's Printer, 2012. p. 60

${ }^{25}$ DUNLOP; BUCKWOLD. Debt Recovery in Alberta. Toronto: Carswell, 2012. p. 147-148.
} 
suscetível ao bel prazer do credor na escolha do instrumento, e não necessariamente o menos gravoso ao devedor. ${ }^{26}$

Com o objetivo de unificar o pré-julgamento na legislação canadense e fornecer requisitos e procedimentos mais claros, a Lei Uniforme propõe a adoção da tutela cautelar como única forma de tutela provisória, agilizando a atuação jurisdicional do tribunal enquanto fornece flexibilidade para ordenar uma série de medidas específicas de preservação, de modo que o judiciário está autorizado a emitir todo tipo de ordem necessária para a preservação de bens. ${ }^{27}$

O requerente que deseja obter uma ordem de preservação deve cumprir vários requisitos, dentre eles a conhecida double-bill: probabilidade do direito e risco ao resultado útil do processo. Ainda, o tribunal deve avaliar qual das partes sofrerá maior prejuízo com a concessão ou recusa da tutela, enquanto se aguarda a decisão final sobre o mérito. ${ }^{28}$

Sob a óptica do devedor, Lei Uniforme também impede a aplicação de medidas que interfiram na capacidade do réu de pagar suas despesas de subsistência, de gestão de negócios ou relativos à sua defesa no processo. ${ }^{29}$

Assim, a tutela cautelar sob a égide da Lei Uniforme fornece um substituto viável para os instrumentos anteriormente disponíveis, eliminando sobreposição, confusão e a perspectiva de abuso e uso indevido, com melhores soluções para os credores e devedores.

\subsection{Registro de bens móveis}

Excetuando Quebec, todas as províncias canadenses promulgaram leis que regem os direitos dos credores com garantia real de penhor. ${ }^{30}$ Apresentada pela primeira vez em Ontário, essas leis foram responsáveis pelo desenvolvimento do Registro de Bens Móveis, um banco de dados computadorizado e pesquisável que serve como uma plataforma para o registro de penhores. ${ }^{31}$

\footnotetext{
${ }^{26}$ ALBERTA LAW REFORM INSTITUTE, op. cit., p. 146

${ }^{27}$ LAW REFORM COMISSION OF NOVA SCOTIA, op. cit., p. 26

${ }^{28}$ UNIFORM LAW CONFERENCE OF CANADA, op. cit., Seção 16 (1).

${ }^{29}$ Ibidem, Seção 17 (2).

${ }^{30}$ BUCKWOLD, op. cit. p. 86

${ }^{31}$ DUNLOP; BUCKWOLD, op. cit., p. 257-258.
} 
O sucesso do Registro de Bens Móveis, especialmente em relação aos contratos de financiamento, inspirou a adoção do registro como um instrumento judicial em várias províncias, previsto na Lei Uniforme, consolidando uma interface entre os sistemas que regem a proteção de credores garantidos e quirografários.

De acordo com a Lei Uniforme, o ato de registro da decisão ou do ofício judicial é requisito para determinação da prioridade de reivindicação no concurso entre credores com penhor sobre um mesmo bem pessoal do devedor. ${ }^{32}$ Além disso, mesmo para os credores quirografários, o ato de registro é condição prévia para a instauração do processo executivo, servindo de notificação a terceiros potencialmente interessados no bem sobre a existência de controvérsia judicial sobre ele. ${ }^{33}$

Essa condição também contribui para a utilidade do Registro de Bens Móveis e facilita a avaliação do risco por potenciais credores, ao permitir que quem simplesmente navegue na base de dados possa determinar em que medida um patrimônio é afetado por restrições prévias. ${ }^{34}$

\subsection{Penhora de créditos}

Sob a égide da legislação pré-reforma, a penhora (ou indisponibilidade) de créditos desempenhou papel importante na satisfação das reivindicações do credor após (e mesmo antes) da sentença. Sem dúvida, a penhora de créditos é uma opção muito difundida entre os credores que desejam ver suas sentenças e títulos executados com relativa rapidez e sem o ônus de apreender e vender ativos, com valor de mercado muitas vezes reduzido. ${ }^{35}$

Todavia, existiam claras limitações a este procedimento, vez que alguns tipos de ativos, como créditos conjuntos ou judiciais, bem como obrigações futuras e/ou condicionais, simplesmente não eram alcançáveis. Além disso, a penhora de créditos sobre obrigações de terceiro vinculava apenas as dívidas vencidas ou vincendas no momento de emissão da ordem de constrição. Ainda, no que diz respeito à penhora ou restrição de parte dos salários do devedor, a ordem de penhora atingia apenas as remunerações a serem pagas

\footnotetext{
${ }^{32}$ BUCKWOLD, loc. cit.

${ }^{33}$ WOOD, Roderick J. The Reform of Judgment Enforcement Law in Alberta. Can. Bus. LJ, v. 25, 1995.p. 115.

${ }^{34}$ DUNLOP; BUCKWOLD, op. cit., p. 256.

${ }^{35}$ WOOD, op. cit., p. 121
} 
até sete dias após a emissão da decisão judicial, exigindo a reemissão de ordens de penhora mensais ou bimestrais para cada período de pagamento. ${ }^{36}$

A Lei Uniforme apresenta uma alternativa a este sistema, substituindo-o pelo amplo instrumento de penhora de contas e créditos devidos a um devedor, de modo que, passando a ser considerada como "bem móvel"37, as contas do devedor se tornam passíveis de mera apreensão, observadas as regras e limites de penhorabilidade previstos em lei..$^{38}$

Uma alteração importante trazida pelo Ato Uniforme é que uma ordem de penhora se aplica a créditos futuros do devedor a serem pagos em até 12 meses após a decisão de constrição, fornecendo uma modalidade de penhora recorrente. ${ }^{39}$

Embora essas mudanças no procedimento de penhora de créditos representem um grande ganho para os credores que buscam satisfazer suas execuções, elas afetaram o tema das impenhorabilidades, que será discutido no próximo item: uma vez que a penhora recorrente tem um impacto significativo sobre os salários, tornando mais fácil para os credores alcançarem esse tipo de valor, políticas de impenhorabilidade mais generosas foram elaboradas a fim de contrabalancear os direitos ampliados dos credores. ${ }^{40}$

\subsection{Impenhorabilidades}

Em geral, todos os bens do devedor estão sujeitos à expropriação para fins da execução, conforme prescreve o princípio da exigibilidade universal, que norteia os processos de execução civil sob a Lei Uniforme. No entanto, é comum que alguns tipos de bens sejam propositadamente excluídos do rol de penhorabilidade por uma razão social, a fim de permitir que os devedores mantenham a si e a seus dependentes em padrões razoáveis de subsistência. ${ }^{41}$

\footnotetext{
${ }^{36}$ FINLAY, Robert. A. In Search of a Remedy: The Case For Reforming British Columbia's Judgment Enforcement Regime. The Advocate, v. 66, p. 21, 2008.

37 "Personal property", na terminologia canadense.

${ }^{38}$ BRITISH COLUMBIA LAW INSTITUTE. Report on the Uniform Civil Enforcement of Money Judgments Act. $2005 . \quad$ Available at: <http://www.bcli.org/sites/default/files/Unif_Civil_Enf_Money_Judgments_Act_Rep.pdf>, p. 60

${ }^{39}$ UNIFORM LAW CONFERENCE OF CANADA, op. cit., Seção. 97 (1) (b).

${ }^{40}$ WOOD, op. cit., p. 122.

${ }^{41}$ ALBERTA LAW REFORM INSTITUTE, op. cit., p. 254-255.
} 
A história da legislação de impenhorabilidades no Canadá segue o caminho do desenvolvimento descoordenado, descrita como confusa, ultrapassada e inadequada às condições econômicas e sociais modernas. Tanto a inflação quanto o êxodo rural tiveram impactos significativos na economia e na forma como as pessoas lidam com seus bens, mudanças que as políticas de penhorabilidade não acompanharam, conferindo pouca proteção a devedores vulneráveis. ${ }^{42}$

Embora não tenha como objetivo recriar os regramentos sobre penhorabilidade do zero, a Lei Uniforme visa resolver as principais questões em torno deste assunto, prevendo um conjunto razoável de bens impenhoráveis, além de uma estrutura menos sujeita à obsolescência. ${ }^{43}$ Assim, o ato uniforme dispõe de uma lista de bens que não são passíveis ao procedimento de expropriação, incluindo, mas não se limitando a alimentos, vestuário cotidiano, eletrodomésticos e ferramentas de trabalho. ${ }^{44}$

Ainda, considerando que a penhora de créditos é um recurso estratégico e frequentemente utilizado para execução das obrigações de pagar quantia, é fundamental que sejam previstas impenhorabilidades cuidadosas a fim de assegurar um padrão mínimo de vida ao devedor e seus dependentes.

Por este motivo, o Ato Uniforme protege uma parte da renda do devedor, vencida ou a ser paga. ${ }^{45}$ De acordo com a fórmula proposta, cada província deve determinar os valores mínimo e máximo protegidos de penhora, baseados em quantia razoável e necessária para sustentar o devedor e seus dependentes, durante o determinado período.

Por exemplo, na província de Alberta, determinou-se como impenhorável a quantia mínima mensal de 800 dólares canadenses, acrescida de 50\% do salário que excede este valor, até um teto rígido de 2.400 dólares canadenses mensais. Em Saskatchewan, o mínimo estabelecido é de 1.500 dólares canadenses mensais, acrescidos de $70 \%$ do salário excedente. Caso o devedor possua dependentes, estes valores são acrescidos em 200 dólares canadenses em Alberta e 300 dólares canadenses em Saskatchewan, por dependente. ${ }^{46}$

A lei prescreve que, a pedido do devedor, do credor, do oficial de execução ou do administrador judicial, o tribunal pode aumentar ou reduzir o montante dos rendimentos

\footnotetext{
${ }^{42}$ DUNLOP, op. cit., p. 449.

${ }^{43}$ BRITISH COLUMBIA LAW INSTITUTE, op. cit., p. 17

${ }^{44}$ UNIFORM LAW CONFERENCE OF CANADA, op. cit., Seção 159 (1).

${ }^{45}$ Ibidem, Seção 165.

${ }^{46}$ LAW COMMISSION OF NOVA SCOTIA, op. cit., Apêndice III.
} 
impenhoráveis, de acordo com as circunstâncias particulares, o que permite a definição de disposições mais flexíveis e amoldados ao caso concreto. Além disso, o uso de regulamentos infralegais para definir as quantias impenhoráveis visa manter esses valores atualizados à realidade contemporânea, vez que podem ser facilmente alterados pelo governo, dispensando o crivo da assembleia legislativa. ${ }^{47}$

\section{CONSIDERAÇÕES COMPARATIVAS SOBRE OS SISTEMAS DE EXECUÇÃO NO BRASIL E NO CANADÁ}

No tópico anterior, as principais características da Uniform Civil Enforcement of Money Judgments Act foram discutidas, permitindo que, adiante, seja realizada a comparação de suas principais disposições com o regramento processual civil brasileiro. Assim, serão destacadas as semelhanças, diferenças e possíveis contribuições que a experiência canadense pode oferecer para o cumprimento das obrigações de pagar quantia no direito brasileiro.

\subsection{Políticas de impenhorabilidade}

Conforme exposto no item supra, o princípio da exigibilidade universal é a pedra angular da reforma dos sistemas de execução no Canadá. Assim, a menos que explicitamente excluídos por lei, todos os bens do devedor estão sujeitos à expropriação para satisfazer uma obrigação de pagar quantia consubstanciada em uma decisão judicial ou título executivo extrajudicial.

O Brasil também adotou o princípio da exigibilidade universal como um dos pilares de seu sistema de execução e cumprimento de sentença, de modo que a maior parte do patrimônio do devedor está sujeita à expropriação no cumprimento de suas obrigações. No entanto, as políticas de impenhorabilidade no Brasil e no Canadá diferem em aspectos substanciais.

Enquanto a impenhorabilidade sobre salários nos sistemas reformados canadenses é definida dentro de valores mínimos e máximos razoáveis, de acordo com regulamentos

\footnotetext{
${ }^{47}$ Ibidem, Seção 168.
} 
específicos de cada província ${ }^{48}$, no Brasil, o Código de Processo Civil estabelece um valor universal impenhorável, correspondendo a 50 vezes o valor do salário mínimo vigente. Além disso, poupanças de até 40 vezes o equivalente ao salário mínimo também estão isentas. ${ }^{49}$

O imóvel residencial do devedor desde que quitado, também está coberto pela impenhorabilidade prevista em lei e não há limites máximos definidos para o valor da propriedade. Em tese, um devedor pode morar em uma mansão luxuosa, mas não será coagido a pagar algumas centenas de reais em uma execução se essa casa for sua única residência. ${ }^{50}$ Por outro lado, no Canadá, ainda que constitua a residência do devedor, se o valor do imóvel ultrapassar o teto estabelecido pelo regulamento provincial, ele poderá ser vendido e o produto arrecadado para o pagamento da dívida judicial. ${ }^{51}$

Em algumas situações, a política brasileira de impenhorabilidades não parece se adequar ao propósito original de garantir um padrão de vida decente aos devedores vulneráveis e a seus dependentes, por vezes prejudicando credores que também sofrem de dificuldades financeiras. Certamente, uma reforma na política de impenhorabilidades brasileira poderia ser positiva, beneficiando-se da experiência canadense, com base na definição valores mínimos e máximos razoáveis para a impenhorabilidade relativa de salários e imóveis.

\subsection{Procedimento de registro de restrições em cartórios}

Com o objetivo de promover uma interface entre os sistemas que regem a proteção de credores garantidos e quirografários, o cadastro de bens previsto pela Lei Uniforme canadense facilita o processo de determinação da prioridade de credores concorrentes e fornece informações relevantes para terceiros potencialmente interessados no ativo.

\footnotetext{
${ }^{48}$ Por exemplo, na província de Alberta, há uma impenhorabilidade de rendimentos mínimos de $\$ 800$ por mês, mais $50 \%$ do excedente, até uma isenção máxima de \$ 2.400 por mês, mais \$200 por dependente. Em Saskatchewan, a impenhorabilidade mínima é de $\$ 1.500$ por mês, mais $\$ 300$ para cada dependente, mais $70 \%$ do excedente. Em ambos os casos, um credor ou devedor judicial pode requerer ao tribunal o aumento ou redução dos valores mínimos e máximos de impenhorabilidade. LAW COMISSION OF NOVA SCOTIA, op. cit., Apêndice III.

${ }^{49}$ Não se olvidam aqui as flexibilizações jurisprudenciais sobre a impenhorabilidade destes valores, como nas dívidas de alimentos ou condominiais, que, no entanto, carecem de sistemática e codificação.

${ }^{50}$ Cf. STJ, RESp n ${ }^{\circ}$ 1.351.571/SP, Quarta Turma, Rel. Des. Luis Felipe Salomão, j. em 27/09/2016.

${ }^{51}$ UNIFORM LAW CONFERENCE OF CANADA, op. cit., Seção 159 (1) (e).
} 
Nos termos do Código Civil Brasileiro, é obrigatório que as restrições relativas a bens imóveis sejam registradas em cartório público competente, a fim de promover efeitos contra terceiros. No entanto, ao contrário da Lei Uniforme canadense, segundo o qual a averbação da sentença é uma exigência para o início do processo de execução, este procedimento é facultativo ao credor brasileiro.

Desde 2006, os credores brasileiros podem registrar certidão premonitória do processo de execução (art. 828, CPC) em cartórios públicos. Esse procedimento diminui a capacidade do devedor de lidar com seus bens afetados, sendo todas as transferências feitas após o registro presumidas fraudulentas - pelo menos até que a dívida seja adimplida. Este procedimento também alerta terceiros interessados sobre bens potencialmente litigiosos.

$\mathrm{O}$ procedimento existente poderia ser significativamente mais eficiente se os registros fossem totalmente digitalizados, seguindo o padrão canadense, em vez do antigo sistema baseado em papel - ainda que existam, hoje, plataformas semiautomatizadas para obtenção de documentos cartorários. Diante de tantas serventias, com serviços burocráticos e caros, é difícil para os credores manter o controle de todos os bens do devedor que estão disponíveis para satisfazer uma obrigação, assim como para terceiros de boa-fé evitarem a aquisição de ativos sob litígio que possam ser reavidos judicialmente.

\subsection{Os papéis do sheriff e do juiz no processo de execução}

Conforme discutido anteriormente, a exigibilidade universal e a existência de procedimentos adequados para alcançar os ativos do devedor são questões centrais nas reformas promovidas nos processos civis brasileiro e canadense. No entanto, os indivíduos responsáveis pela condução desses atos (e seus papéis nesta atividade) diferem em cada país.

No Brasil, o processo de execução se assemelha muito a uma ação de conhecimento, em que o devedor pode apresentar uma série de defesas de fato e direito para rebater as reivindicações do credor. Esse é o principal motivo pelo qual um magistrado brasileiro desempenha um papel muito ativo na execução, e também porque esse procedimento pode ser extremamente moroso.

Por outro lado, o "sheriff” desempenha um papel central no sistema de execuções canadense. Um credor que deseja executar um título judicial ou extrajudicial deve apresentar 
um mandado de execução emitido pelo tribunal a um xerife ou agência privada sob sua supervisão, que lhes concede autoridade para apreender e vender bens dos devedores. Isso significa que, no Canadá, a execução é basicamente um procedimento administrativo, sem a necessidade de contar com um juiz para coordenar o processo. ${ }^{52}$

Essa mesma técnica de desjudicialização da execução já foi adotada em diversas jurisdições de tradição romano-germânica, como Portugal, Itália e Espanha. ${ }^{53}$ Estes países vêm se beneficiando da delegação da competência de atos atinentes à execução (citação, penhora, busca e expropriação de bens etc.) a agentes públicos e/ou privados, o que reduz reduz a intervenção do Poder Judiciário sobre a execução, ${ }^{54}$ já que, em regra, mantém-se a competência do órgão jurisdicional estatal apenas para decidir questões que ocasionalmente possam surgir durante o procedimento. ${ }^{55}$

A adoção de um sistema de execução extrajudicial no Brasil (ainda que misto) já foi discutida na academia e poderia contribuir para um procedimento de expropriação mais rápido e eficiente. ${ }^{56}$

\subsection{Penhora de créditos e o uso da tecnologia da informação pelas Cortes}

Entre as várias técnicas disponíveis para alcançar os bens de um devedor, a penhora de crédito é um método de execução particularmente popular. A penhora de contas bancárias, salários, créditos de terceiros e outros tipos de ativos líquidos é relativamente fácil, barata e efetiva, especialmente considerando que nenhum procedimento de venda é necessário para atingir o resultado final desejado: dinheiro.

\footnotetext{
${ }^{52}$ BUCKWOLD, Tamara. From Sherwood Forest to Saskatchewan: The Role of the Sheriff in a Redesigned Judgment Enforcement System. Sask. L. Rev., v. 66, p. 219, 2003.

${ }^{53}$ RODRIGUES, Marco Antonio; RANGEL, Rafael Calmon. O procedimento extrajudicial pré-executivo lusitano (PEPEX): algumas lições para o sistema brasileiro. In: Revista de Processo, vol, v. 282, n. 2018, p. 455-471, 2018.

${ }^{54}$ FIGUEIRA JÚNIOR, Joel Dias. Execução simplificada e a desjudicialização do processo civil. In: ALVIM NETTO, José Manoel de Arruda; et al (coord.). Execução civil e temas afins do CPC/1973 ao Novo CPC: estudos em homenagem ao professor Araken de Assis. São Paulo: Editora Revista dos Tribunais, p. 579, 2014. ${ }^{55}$ LAMÊGO, Guilherme. Execução extrajudicial e arbitragem: proposta para uma execução extrajudicial arbitral no Brasil. São Paulo; Revista de Processo, vol, v. 286, n. 2018, pp. 505-538.

${ }^{56}$ NEVES, Fernando Crespo Queiroz. Execução extrajudicial. Tese (Doutorado em Direito) - Faculdade de Direito, Pontifícia Universidade Católica. São Paulo, 2016. RIBEIRO, Flávia Pereira. Desjudicialização da execução civil. 2012. 288 f. Tese (Doutorado em Direito). Faculdade de Direito da Pontifícia Universidade Católica de São Paulo, São Paulo. CILURZO, Luiz Fernando. A desjudicialização na execução por quantia. 2016. 247 f. Tese (Doutorado em Direito) - Faculdade de Direito da Universidade de São Paulo, São Paulo. pp. 109-110.
} 
Um credor canadense que deseje executar a penhora de uma dívida deve fornecer ao oficial de execução instruções detalhadas sobre o devedor e seus ativos, incluindo o nome do empregador, endereço e número de telefone, bem como os dados completos da agência bancária em que ele possui contas. De posse dessas informações, o xerife entregará aos controladores das contas um ofício, ordenando que os créditos detidos pelo devedor sejam pagos à autoridade administrativa. ${ }^{57}$

Como se vê, o sucesso da penhora de crédito no Canadá depende da existência de dados sobre o devedor e seus bens, de modo que a ausência de tais informações pode inviabilizar o procedimento expropriatório. Embora o sistema canadense preveja métodos mandamentais de obtenção de informações, como formulários e questionários, e imponha multas e até prisão para aqueles que forem condenados por desacato diante da recusa a fornecer dados ou pelo fornecimento de informações falsas, esses instrumentos são mais lentos e menos confiáveis do que os disponíveis no Brasil. ${ }^{58}$

No Brasil, no início dos anos 2000, entidades governamentais firmaram convênios para desenvolver plataformas semiautomáticas de comunicação entre juízes e órgãos cruciais. O resultado foi a criação dos sistemas BacenJud e Infojud, desenvolvidos para atender às ordens judiciais de arresto e penhora de contas bancárias e aplicações, além de fornecer informações financeiras e fiscais dos devedores. Ainda, o Renajud permitiu contato direto entre magistrados e o Departamento Nacional de Trânsito, possibilitando o levantamento de informações e cadastros de restrições sobre veículos. ${ }^{59}$

Esse novo sistema mudou radicalmente o sistema de execução de sentenças no Brasil, permitindo aos juízes dar mais efetividade às suas decisões, solicitando informações aos devedores e realizando operações por meio de seus computadores, de maneira rápida e barata. ${ }^{60}$ Todavia, a jurisprudência canadense tem se demonstrado pouco adepta e permissiva à possibilidade adoção de sistemas como este no país, devido à sua legislação de proteção de dados bastante restritiva. ${ }^{61}$

\footnotetext{
${ }^{57}$ UNIFORM LAW CONFERENCE OF CANADA, op. cit., Seção 96.

${ }^{58}$ BUCKWOLD, The Reform of Judgment Enforcement Law in Canada: An Overview and Comparison of Models for Reform, p. 80-81.

${ }^{59}$ JOIA, Luiz Antonio. O impacto dos esforços de governo para governo no capital intelectual das organizações públicas. Government Information Quarterly, v. 25, n. 2, pág. 256-277, 2008. p. 266.

${ }^{60}$ FRAGALE FILHO, Roberto. O uso das TIC nos tribunais brasileiros. Revista Eletrônica de Governo Eletrônico, v. 7, n. 4, pág. 349-358, 2009. p. 353-354.

${ }^{61}$ Cf. Royal Bank of Canada v. Trang, 2016 SCC 50.
} 


\section{CONCLUSÕES}

Em todo o mundo, o cumprimento das obrigações de pagar quantia depende fortemente da expropriação de bens penhoráveis dos devedores e, embora não pareça um processo complicado à primeira vista, muitos são os obstáculos a uma execução bem sucedida.

Os credores brasileiros sofrem com processos de execução demorados, que parecem apenas uma extensão da ação original movida por eles. Muitos são os devedores que se aproveitam disso para apresentar todo tipo de defesa protelatória, além de ocultar e/ou dilapidar seu patrimônio, a fim de tornar infrutífero o processo de execução.

Ainda que a legislação brasileira ofereça ferramentas interessantes para a execução de ordens e solicitação de informações a instituições financeiras, bem como procedimentos para recuperar bens transferidos de forma fraudulenta, esses instrumentos não têm se mostrado suficientes para proporcionar a efetividade que os credores tanto esperaram.

Esta é uma das razões pelas quais se recebeu com grande entusiasmo as recentes reformas e considerou-se eficaz a possibilidade de suspensão de carteiras de habilitação, passaportes, cartões de crédito e outras medidas atípicas, com foco nas particularidades de cada devedor, a fim de descobrir sua "fraqueza" e induzi-lo a revelar seus bens.

A natureza punitiva de tais medidas, bem como se seu uso pode conflitar com os direitos fundamentais do devedor, ainda estão em debate na academia e nos tribunais brasileiros. Por outro lado, o Canadá parece ter chegado a uma conclusão menos polêmica: simplesmente não são aceitáveis. E, embora recuse o uso desse tipo de remédio, a lei canadense se desenvolveu para fornecer outras alternativas aos credores: um procedimento de execução rápido, conduzido administrativamente; um registro de bens móveis para localizar e restringir os ativos dos devedores; políticas de impenhorabilidade adequadas e assim por diante.

É claro que o modelo de direito legislado brasileiro é, em muitos aspectos, mais rigoroso do que a canadense, mas os procedimentos de cumprimento são consideravelmente mais fracos, razão pela qual encontrar novas perspectivas e soluções é fundamental para se alcançar um sistema judicial justo e eficaz. 
Quaisquer comparações entre os sistemas brasileiro e canadense devem ser feitas e interpretadas com cautela, considerando as diferenças significativas entre os sistemas de Common Law e de Civil Law e, até mesmo, as distinções culturais, sociais e econômicas entre os dois países. No entanto, é possível observar como em seus sistemas de execução há semelhanças, compartilhando os mesmos princípios e pedras angulares, de modo que alguns fundamentos e procedimentos da legislação canadense poderiam gerar reflexões de aplicação ao sistema de cumprimento de sentenças/execução brasileiro, com vistas ao seu aperfeiçoamento.

\section{REFERÊNCIAS}

ALBERTA LAW REFORM INSTITUTE. Prejudgment Remedies for Unsecured Claimants. Report nº 50, 1988.

BILLINGSLEY, Barbara. Evolution, Not Revolution: Canada's Constitutional History and the Constitution Act, 1867. LawNow, v. 37, p. 8, 2012.

BONATO, Giovanni. As reformas da execução no processo civil italiano. Civil Procedure Review, v. 6, n. 3, p. 129-158, 2015.

\section{BRITISH COLUMBIA LAW INSTITUTE. Report on the Uniform Civil Enforcement of Money Judgments Act. 2005. Available at: $<$ http://www.bcli.org/sites/default/files/Unif_Civil_Enf_Money_Judgments_Act_Re p.pdf $>$.}

BUCKWOLD, Tamara. From Sherwood Forest to Saskatchewan: The Role of the Sheriff in a Redesigned Judgment Enforcement System. Sask. L. Rev., v. 66, p. 219, 2003. . The Reform of Judgment Enforcement Law in Canada: An Overview and Comparison of Models for Reform. Sask. L. Rev., v. 80, 2017.

CINTRA, Antonio Carlos Araujo; GRINOVER. Ada Pellegrini; DINAMARCO, Cândido Rangel. Teoria Geral do Processo. 26a ed. São Paulo: Malheiros, 2010.

CILURZO, Luiz Fernando. A desjudicialização na execução por quantia. 2016. 247 f. Tese (Doutorado em Direito) - Faculdade de Direito da Universidade de São Paulo, São Paulo. pp. 109-110.

CUMING, Ronald C.C.; LAYH, Donald. The Saskatchewan Enforcement of Money Judgments Act: Commentary and Analysis. Regina: Queen's Printer, 2012.

DUNLOP, Charles Richard Bentley. Creditor-Debtor Law in Canada. $2^{\text {nd }}$ ed. Toronto: Carswell, 1995.

; BUCKWOLD, Tamara. Debt Recovery in Alberta. Toronto: Carswell, 2012. 
FIGUEIRA JÚNIOR, Joel Dias. Execução simplificada e a desjudicialização do processo civil. In: ALVIM NETTO, José Manoel de Arruda; et al (coord.). Execução civil e temas afins do CPC/1973 ao Novo CPC: estudos em homenagem ao professor Araken de Assis. São Paulo: Editora Revista dos Tribunais, p. 579, 2014.

FINLAY, Robert. A. In Search of a Remedy: The Case For Reforming British Columbia's Judgment Enforcement Regime. The Advocate, v. 66, p. 21, 2008.

FRAGALE FILHO, Roberto. O uso das TIC nos tribunais brasileiros. Revista Eletrônica de Governo Eletrônico, v. 7, n. 4, pág. 349-358, 2009.

GAJARDONI, Fernando da Fonseca. A revolução silenciosa da execução por quantia. JOTA. Brasília DF: 24 ago. 2016. Disponível em <https://www.jota.info/opiniao-eanalise/artigos/a-revolucao-silenciosa-da-execucao-por-quantia-24082015>.

GLEIXNER, Micheline A.; LEBLANC, Natalie H.; MORISSET, Sacha D. The New Brunswick Judgment Enforcement Act: Has Its Time Finally Come. UNBLJ, v. 63, p. 280, 2012.

HILL, Flávia Pereira. Desjudicialização da execução civil: reflexões sobre o projeto de lei $\mathrm{n}^{\circ}$ 6.204/2019. Revista Eletrônica de Direito Processual, v. 21, n. 3, 2020

O procedimento extrajudicial pré-executivo (Pepex): reflexões sobre o modelo português, em busca da efetividade da execução no Brasil. In: MEDEIROS NETO, Elias Marques de; RIBEIRO, Flávia Pereira. Reflexões sobre a Desjudicialização da Execução Civil. Curitiba: Juruá. 2020. pp. 305-322.

JOIA, Luiz Antonio. O impacto dos esforços de governo para governo no capital intelectual das organizações públicas. Government Information Quarterly, v. 25, n. 2, pág. 256277, 2008.

LAMÊGO, Guilherme. Execução extrajudicial e arbitragem: proposta para uma execução extrajudicial arbitral no Brasil. São Paulo; Revista de Processo, vol, v. 286, n. 2018, pp. 505-538.

LAW REFORM COMISSION OF NOVA SCOTIA. Final Report: Enforcement of Civil Judgments. 2014. Disponível em <http://www.canlii.org/t/7f5>.

MEDEIROS NETO, Elias Marques. O artigo 139, IV, do novo código de processo civil: a atipicidade dos meios executivos. In: JATAHY, Carlos Roberto; ALMEIDA, Diogo Assumpção Rezende de; AYUOUB, Luiz Roberto (Coord.). Reflexões sobre o novo código de processo civil. Rio de Janeiro: FGV Editora, 2016.

NEVES, Fernando Crespo Queiroz. Execução extrajudicial. Tese (Doutorado em Direito) Faculdade de Direito, Pontifícia Universidade Católica. São Paulo, 2016.

RIBEIRO, Flávia Pereira. Desjudicialização da execução civil. 2012. 288 f. Tese (Doutorado em Direito). Faculdade de Direito da Pontifícia Universidade Católica de São Paulo, São Paulo. 
. Desjudicialização da execução civil: mito ou realidade. Migalhas. São Paulo

SP: $\quad 18 \quad$ out. $2019 . \quad$ Disponível em

<https://migalhas.uol.com.br/depeso/313285/desjudicializacao-da-execucao-civilmito-ou-realidade>.

RODOVALHO, Thiago. O necessário diálogo entre a doutrina e a jurisprudência na concretização da atipicidade dos meios executivos. JOTA. Brasília DF: 21 set. 2016. Disponível em < https://www.jota.info/opiniao-e-analise/artigos/o-necessario-dialogoentre-doutrina-e-jurisprudencia-na-concretizacao-da-atipicidade-dos-meiosexecutivos-21092016>.

RODRIGUES, Marco Antonio; RANGEL, Rafael Calmon. O procedimento extrajudicial pré-executivo lusitano (PEPEX): algumas lições para o sistema brasileiro. In: Revista de Processo, vol, v. 282, n. 2018, p. 455-471, 2018.

UNIFORM LAW CONFERENCE OF CANADA. Uniform Civil Enforcement of Money Judgments. 2005. Disponível em <http://www.bcli.org/project/uniform-civilenforcement-money-judgments-act $>$.

WOOD, Roderick J. The Reform of Judgment Enforcement Law in Alberta. Can. Bus. LJ, v. 25, 1995. 